\title{
POLÍTICAS LINGUÍSTICAS EDUCATIVAS: EFEITOS DA CONTEMPORANEIDADE
}

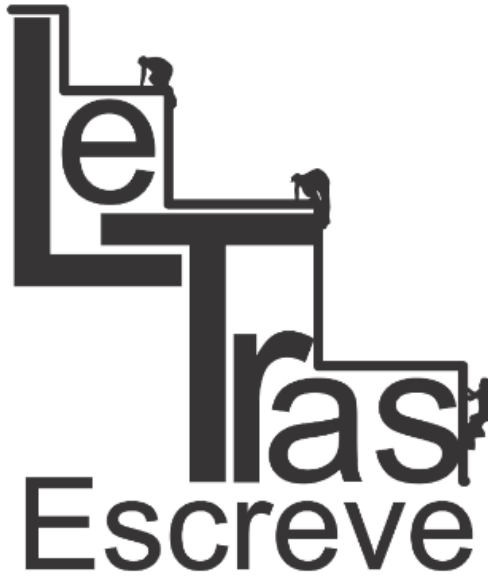

(ISSN 2238-8060)
RESUMO: As transformações tecnológicas transcorridas na passagem do século $\mathrm{XX}$ para o $\mathrm{XXI}$, modificando profundamente os modos de comunicar entre os indivíduos « intra » e « inter » nacionalmente e, por conseguinte, o papel das línguas no mercado de trabalho global, estão refletidas nas políticas linguísticas em curso na atualidade. Tais políticas encontram-se circunscritas por diversos fatores que não são apenas mercadológicos, exigindo uma observação criteriosa por parte dos agentes político-linguísticos e avaliadores. A proposta deste trabalho é delinear os principais viéses de debate em torno da política linguística educativa nos dias atuais e estabelecer os diferentes focos de discussão. Nossa análise busca situar políticas periféricas, não hegemônicas que confrontam a ideologia da prevalência de políticas globais sobre as locais e refletir sobre as repercussões destas políticas no âmbito de objetivos educacionais que vislumbrem os ideais do plurilinguismo, da tolerância e do respeito à diversidade cultural.

PALAVRAS-CHAVE: Política Linguística. Línguas Estrangeiras. Ensino.

\section{EDUCATIONAL LANGUAGE POLICIES: CONTEMPORANEITY EFFECTS}

ABSTRACT: The technological changes that have taken place between the 20 th and 21 st centuries, profoundly modifying the modes of communication between 'intra' and 'inter' individuals, and therefore the role of languages in the global labor market, are reflected in the Current linguistic policies. These policies are circumscribed by several factors that are not just marketoriented, requiring careful observation by political-linguistic agents and evaluators. The purpose of this paper is to outline the main biases of the debate around the linguistic policy of education in the present day and to establish the different focuses of discussion. Our analysis seeks to situate peripheral, non-hegemonic policies that confront the ideology of the prevalence of global policies on localities and reflect on the repercussions of these policies within the scope of educational objectives that glimpse the ideals of plurilingualism, tolerance and respect for cultural diversity.

KEY WORDS: Linguistic Policy. Foreign languages. Teaching.

\section{Introdução}

Os processos de globalização e de abertura da economia, a comunicação intercultural e o alto ritmo de progresso científico e tecnológico exercem pressões cada vez maiores sobre nossas vidas, exigindo o desenvolvimento de competências em uma ou mais

\footnotetext{
${ }^{1}$ Dra em Políticas Linguísticas pela Universidade Federal Fluminense (UFF), Professora da Universidade do Estado do Amapá (UEAP). Email: kellyday@uol.com.br.
} 
línguas estrangeiras que possibilitem a participação em igualdade de condições na cultura global, sem perder o sentido de pertencimento a uma dada cultura.

Se antigamente estudava-se uma língua estrangeira para conhecer a cultura, a política e os costumes de outros povos, na atualidade, a economia, onde quer que ela se manifeste, é a grande mola propulsora do ensino de línguas no mundo. Esta nova realidade faz da aprendizagem de línguas estrangeiras uma exigência absoluta que influencia em grande medida os projetos de política linguística dos países e mesmo de instâncias outras, como os grandes mercados, além de colocá-las em uma rede de concorrência que se fundamenta na busca e na manutenção da influência política e econômica.

Esse processo irreversível requer um grande esforço de adaptação de todas as sociedades às novas realidades e coloca os governos diante de novos desafios que precisam ser minimamente enfrentados, seja no âmbito das políticas de ensino, de manutenção e/ ou proteção das línguas consideradas maternas, seja no campo das políticas de ensino de línguas adicionais ou estrangeiras.

Nesses novos tempos, a regulação da educação é cada vez mais realizada em contextos supranacionais, impondo, por um lado, um padrão comum de pensar a formação dos alunos e de organizar o currículo, e por outro, práticas curriculares homogêneas e orientadas para a "eficiência" dos resultados de aprendizagem. O que não significa, necessariamente, sucesso. Na contramão desse processo, muitos grupos têm buscado, paralelamente, reforçar suas identidades regionais e suas características culturais através do reforço de seus laços, entre eles os linguísticos (DAY, 2016).

Essa globalização educacional supracitada traduz-se em "formações centradas na aquisição de competências, ligadas às ciências, à matemática, às línguas e às tecnologias de informação e comunicação, com vistas à edificação da aldeia do conhecimento" (PACHECO; PEREIRA, 2007, p. 376). Nesse conjunto, as línguas são veículos culturais por excelência, e o processo de ensi- 
no/aprendizagem conduz ao que tem sido nomeado, a justo título, de diálogos de culturas, entre a cultura materna e a cultura estrangeira, entre o universo conhecido e o exterior.

Fala-se em cerca de 6.000 línguas no mundo atual, partilhadas por 200 estados nacionais (físicos e políticos), a titulo de exemplo destacamos a existência de mais de 200 línguas no Brasil, de cerca de 60 línguas autóctones e 340 variedades dialetais no México, mais de 700 línguas na Nova Guiné, um número superior a 1600 línguas na Índia, além do uso de mais de 260 línguas em cidades como Londres, Montreal, Toronto e São Francisco, devido ao alto fluxo migratório da atualidade. Tais dados, por si só, indicam a grande utopia que é a existência de um estado unilíngue e unicultural e diferentes políticas de gestão das línguas no mundo.

\section{Política Linguística na contemporaneidade}

A atual conjuntura política e socioeconômica do mundo contemporâneo coloca as discussões sobre políticas linguísticas em posição de destaque em instâncias tanto administrativas quanto acadêmicas. Diferente do que ocorria ha cerca de 40 anos, quando raros linguistas propunham-se a debater os fundamentos da política linguística no Brasil, as questões políticas relativas ao ensino das línguas ocupam um novo espaço nas universidades e programas de pós-graduação brasileiros.

De modo geral, sem querer exaurir a questão, as Políticas Linguísticas tratam da regulação do uso e das funções que as línguas ocupam na sociedade e que foram, por assim dizer, definidas pelo agente público, pelo estado ou mesmo pela comunidade e referendadas através de aparato legal. Isso inclui a definição de língua nacional, língua oficial, língua estrangeira, língua de ensino, a normatização da língua, reformas, modernização, simplificação estilística, a delimitação dos espaços onde estas línguas podem ser utilizadas, enfim, todas as ações adotadas de forma consciente pelo Estado, através de instrumentos jurídicos ou não e em um âmbito que 


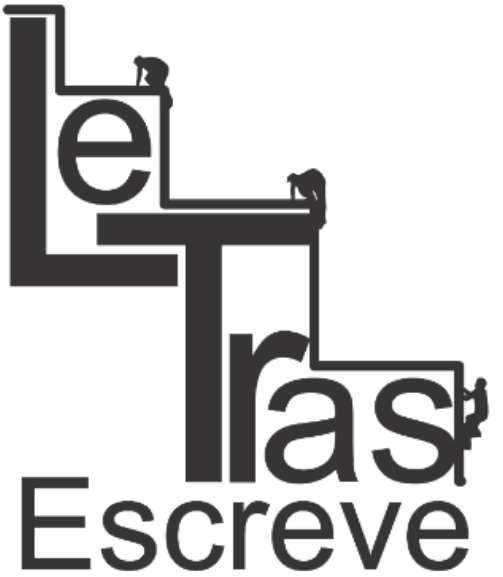

(ISSN 2238-8060) pode ser local, regional, nacional ou mesmo supranacional, como é o caso das decisões de política linguística tomadas pelos mercados mundiais.

Falar de política linguística hoje nos remete a pelo menos duas perspectivas, a primeira é aquela que situa a política linguística numa ótica a-histórica que concebe o domínio a partir de um par conceitual que é política e planificação (HAUGEN, 1959, 1972; CALVET, 1996; SAVEDRA, 2012) ou seja, da percepção de política a partir da formulação de um ideal linguístico e da implementação desse objetivo através, por exemplo, da legislação. Perspectiva essa que inaugurou o campo da política linguística com Heinar Haugen nos anos 60 .

A segunda representa uma ruptura com esse quadro epistemológico, além de constituir um novo enfoque centrado na perspectiva sociopolítica. Nesse cenário que começa a ser desenhado no início do século XX, a política linguística passa a ser vista a partir da junção de três elementos: as representações, as práticas e o gerenciamento. Spolky (2004) concebe que o estudo das políticas linguísticas exige muito mais um olhar para as práticas e representações do que propriamente para o aparato legal.

Em outras palavras, nessa perspectiva, o estudo das políticas linguísticas implica olhar para as políticas a partir das ideologias linguísticas que as subjazem, das práticas e dos usos efetivos registrados em uma dada região, ou seja, através da ecologia linguística e das ações promovidas para manipular o comportamento linguístico de uma comunidade (SPOLKY, 2004, SHOHAMY, 2006). Diferente da perspectiva inicial, parte-se do pressuposto que o agente público não é necessariamente o único que pode promover ações de políticas linguísticas.

Tomando como referência as representações sociais das comunidades relativas às línguas, Schiffman defende que

Política linguística fundamenta-se, em última instância, na cultura linguística, ou seja, no conjunto de comportamentos, suposições, formas culturais, 
preconceitos, sistemas populares de crenças, atitudes, estereótipos, formas de pensar sobre a linguagem e as circunstâncias histórico-religiosas associadas a uma língua específica (SCHIFFMAN 1996, p.5).

Porém, o Estado, como principal articulador de políticas linguísticas, utiliza mecanismos diversos para implementá-las, lançando mão daquilo que Shohamy (2006) denomina de políticas linguísticas ocultas. Tais mecanismos podem tanto ser explícitos, previstos em lei, na constituição, etc.; quanto implícitos - que obviamente não estão declarados, porém são engendrados e implementados através do aparato do Estado. A título de exemplo destas práticas pode-se citar o fornecimento ou não de material didático, o estabelecimento de exames obrigatórios e limitados a línguas especificas, a adoção de vocabulário específico em língua estrangeira em instituições públicas, entre outros.

São estes mecanismos que sustentam as ideologias linguísticas e possibilitam a instauração de políticas homogêneas e hegemônicas em um território, região ou país. Tais mecanismos têm influência direta nas políticas contemporâneas. No caso brasileiro, especificamente, podemos citar, por exemplo, a LDB 9394/96 que delimita explicitamente, por um lado, a língua de escolarização, de alfabetização, o segmento de ensino em que línguas indígenas podem ser ensinadas, o ensino de Libras, de línguas estrangeiras e implicitamente, por outro, reforça uma política de hegemonia da língua portuguesa, deslegitimando as demais línguas brasileiras nas escolas, bem como das línguas inglesa e espanhola, como línguas estrangeiras preferenciais no país. Esses mecanismos estão presentes na política implementada através de programas como o Exame Nacional de Ensino Médio (ENEM) - a legislação brasileira define o direito de escolha, mas não oferece condições efetivas para isso, e o Programa Nacional do Livro didático (PNLD) que segue na mesma linha (DAY, 2016).

Tomando como referência o pensamento de Spolky (2004) e Shohamy, (2006), ressalta-se que os mecanismos implícitos se mos- 
tram mais eficientes e efetivos porque dão a impressão de não serem impositivos quando na verdade o são. E o caso das políticas de reforços às chamadas "ideologias consensuais" que atribuem valor positivo e prestígio a uma língua ou a usos linguísticos específicos em uma dada época e são utilizados para justificar a adoção de políticas impositivas, implícitas ou explicitas que parecem estar legitimadas pelo senso comum. Tais mecanismos constituem-se em ferramentas de criação e sustentação das reais políticas linguísticas do Estado.

Nos termos de Silva,

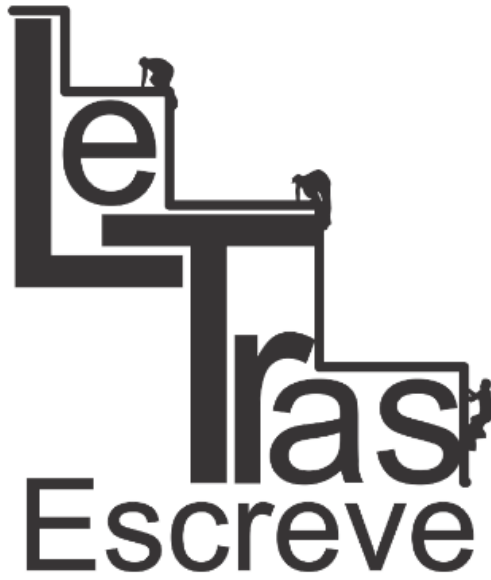

(ISSN 2238-8060)

Os mecanismos de política linguística, em última instância, determinam a forma como a população percebe uma língua específica (suas representações) e, consequentemente, influenciam suas atitudes relativamente a essa língua. Assim, os mecanismos fomentam as práticas sociais da comunidade e, de fato, a real política linguística em vigor na sociedade (SILVA, 2013, P.19).

Nesse âmbito é valido dizer que tanto a política linguística adotada pelo estado do Amapá ${ }^{2}$, no início dos anos 90 para o francês, quanto à política nacional de implantação do espanhol ${ }^{3}$, não nasceram no vazio político-ideológico do Estado, ao contrário, se constituíram no bojo de acordos políticos, sociais e econômicos bem delimitados. Alguns não tão claros ou explícitos, como foi o caso da lei do espanhol, mas com uma forte propaganda ideológica subjacente. De igual maneira situamos a recente reforma do ensino médio (Medida Provisória 746/2016) que tornou a língua inglesa a única língua estrangeira de ensino obrigatório no Brasil.

Esses casos acima exemplificados só reforçam a necessária conscientização de que as políticas linguísticas da atualidade compõem as agendas políticas, ideológicas, sociais e econômicas dos

\footnotetext{
${ }^{2}$ Após a assinatura do acordo-quadro Brasil-França em 1998 e o acordo de cooperação transfronteiriça assinado em 1999, o estado inicia uma série de ações (formação de professores, elaboração de material didático, etc.;) visando tornar a língua francesa a língua estrangeira de oferta obrigatória no estado.

${ }^{3}$ Em 2005 é sancionada a Lei 11.161 que torna o espanhol a língua de oferta obrigatória em todas as escolas de ensino médio no Brasil.
} 


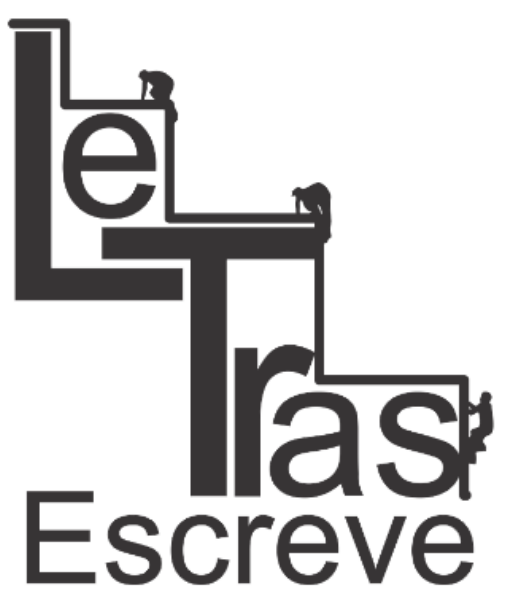

(ISSN 2238-8060)

estados nacionais. E que suas implementações estão sustentadas em ideais políticos que reproduzem e disseminam estratégias de manutenção da unidade linguística nacional, de lealdade políticoideológico, de integração comercial, entre outros, agindo diretamente sobre os comportamentos linguísticos e as práticas sociais relativas às línguas.

No que concerne à condução das políticas linguísticas debatidas pela comunidade científica, identificamos paralelamente dois polos de debates: políticas intervencionistas e políticas liberais.

O polo que pode ser denominado de políticas intervencionistas - trata da gestão dos recursos linguísticos no mundo - propõe uma defesa mais contundente de todas as línguas; maior respeito às ecologias linguísticas, ou seja, às línguas locais, regionais; combate mais incisivo às praticas que levam ao desaparecimento das línguas, entre elas o reforço às políticas hegemônicas regionais surgidas como consequência do combate à expansão do inglês.

Embora pareça contraditório, as políticas intervencionistas veem o nacionalismo linguístico como favorável à manutenção do plurilinguismo. Calvet (2002) explica que o enfraquecimento das línguas nacionais, combatidas em duas frentes, favorece o fortalecimento das línguas vernaculares por um lado e a expansão do inglês como língua internacional, por outro.

Outro polo é o das políticas liberais - defende a livre circulação do mercado das línguas - para estes o desaparecimento ou não de uma língua deve ser visto como processo natural determinado pela correlação de forças entre as línguas. Obviamente essa postura vem ao encontro das tendências políticas e econômicas do mundo contemporâneo, à medida que a ideia de língua única representa uma quebra de barreira para o mercado global, facilitando a troca de mercadorias, tecnologias, bens e serviços de modo geral.

\section{Efeitos da contemporaneidade nas políticas linguísticas edu- cativas}

https:// periodicos.unifap.br/ index.php/ letras

M acapá, v. 6, n. 2, 20 semestre, 2016. 
O atual ensino de línguas estrangeiras está fortemente relacionado às questões geopolíticas e econômicas de uma região assim como às relações político-econômicas com o mercado mundial (RAJAGOPALAN, 2005). A intensa mobilidade física e virtual de pessoas e objetos, intensificada pela mídia e impulsionada pelas novas tecnologias e a relevância da comunicação entre os povos, eleva a importância do ensino e da aprendizagem de línguas no século XXI a um patamar jamais outrora observado. Chega-se então na questão central que atravessa qualquer discussão sobre política linguística na atualidade: o fator plurilinguismo/ multilinguismo na era da sociedade global.

A existência cada vez mais frequente de falantes bilíngues e plurilíngues no mundo amplia as possibilidades de interação entre eles, passando também a constituir lugar comum entre os grupos linguísticos e a determinar, grosso modo, uma hierarquia entre as línguas.

Benéfico para alguns e questionável para outros, o plurilinguismo é um fenômeno de contato linguístico inerente aos nossos tempos. Computadores, celulares, navegação em rede, aplicativos, redes sociais virtuais, entre inúmeras outras ferramentas integram e definem o dia a dia deste início de século e colocam os indivíduos em um sistema de contato linguístico constante. Nesse cenário, o sintagma "Aldeia Global" reveste-se de elementos inter-relacionados e complementares típicos dos nossos dias:

$\checkmark$ Interconexão planetária dos povos através da internet;

$\checkmark$ Integração cada dia mais intensa pelas mídias sociais contato virtual;

$\checkmark$ Velocidade na produção e na troca da informação;

$\checkmark$ Fluxo migratório intenso facilitado por meios de transportes muito mais rápidos e eficazes;

$\checkmark$ Ampliação/redução do mercado de trabalho mundial;

$\checkmark$ Ampliação do mercado das línguas e, por conseguinte do papel econômico que as línguas exercem;

$\checkmark$ Contato linguístico muito mais frequente, mais intenso 


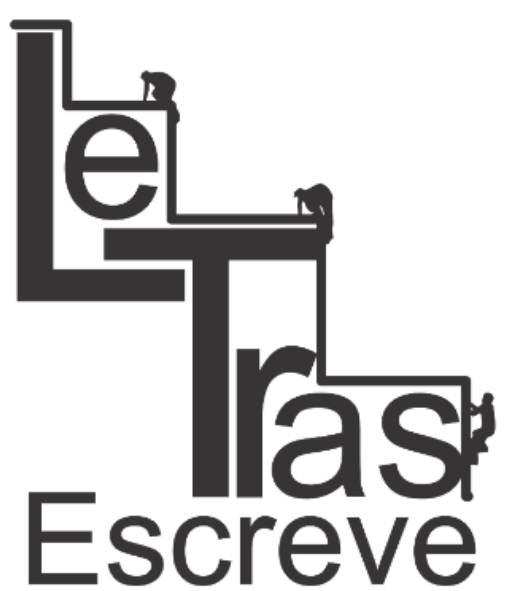

(ISSN 2238-8060) através de diversos meios de comunicação de massa $\mathrm{TV}$, radio, cinema;

$\checkmark$ Interligação política, econômica e ideológica entre nações.

Todavia, ainda que todos esses elementos concorram para uma aproximação entre os povos, eles também evidenciam e colocam em destaque as diferenças. Ora, é no confronto das similaridades e das diferenças que surgem os conflitos. O encurtamento das distâncias físicas e virtuais e um pretenso desaparecimento das fronteiras, alimentado pelos discursos positivos do mercado globalizado faz crer que superados os obstáculos linguísticos, nada mais existe senão o sucesso nas relações interpessoais entre povos de línguas diversas. Em contrapartida, é preciso lembrar que as línguas não são simples sistemas de códigos independentes, neutros e desvinculados de seu contexto social, histórico e, sobretudo, cultural.

Destarte todo debate promovido nas últimas décadas relativo ao valor do plurilinguismo na preservação da diversidade linguística e cultural, na gestão da democracia cultural, a ideia de que o plurilinguismo é prejudicial ao desenvolvimento das nações, além de ser fonte de desunião e ineficiência parece não estar superada. O ideal de língua única comum resiste, legitima o ideal do monolinguismo e se estende inclusive para as políticas de ensino de línguas estrangeiras, na exata medida em que o inglês é política, ideológica e economicamente projetado a língua "sine qua non" do mercado econômico global.

Nesse sentido Bonh (2000, p.124) questiona:

Como priorizar os aspectos e os valores educacionais sobre o treinamento e a prontidão para a produção num sistema de ensino em que o poder político - poder naturalmente coercivo - está intimamente aliado ao poder econômico e o poder ideológico submergiu dentro da voracidade do capitalismo que nem poupou a cultura de suas garras de domínio?

Hamel (2010) ao ponderar sobre a condição hegemônica da 


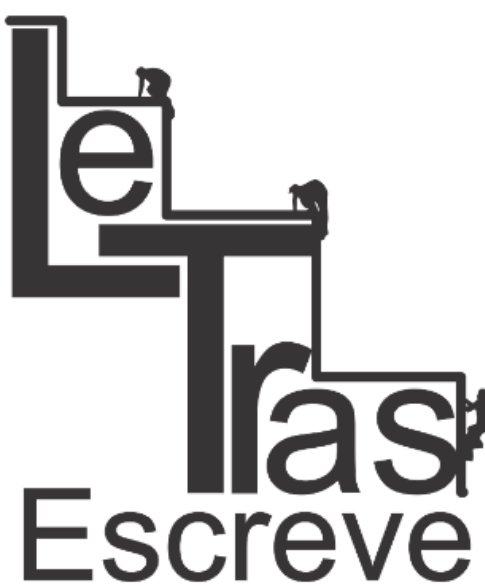

(ISSN 2238-8060) língua inglesa argumenta que são indiscutíveis os benefícios que a difusão de uma língua em escala mundial traz para a comunicação e a interconexão entre os povos diante dos avanços tecnológicos da atualidade, entretanto, não se deve ignorar as desigualdades que esse mesmo processo dissimula, ou seja, os falantes não nativos do inglês confrontam-se com situações assimétricas no uso da língua em comparação aos cidadãos anglófonos e exige-se dos não anglófonos sempre um investimento prévio para que se possa agir naquela língua, muitas vezes dentro de seu próprio território.

O mercado linguístico é, por assim dizer, um dos pilares da idade contemporânea. Capaz de provocar transformações profundas nos programas educacionais, nos currículos e nas organizações de ensino em qualquer parte do planeta na tentativa de atender às demandas do mercado global. A internacionalização das universidades e o intercâmbio de alunos é um exemplo tácito dessa realidade. No entanto, condicionado à eficácia das relações comerciais e à lucratividade das empresas, o ensino de línguas constitui-se atualmente, em certa medida, muito mais como um produto necessário à competitividade econômica que fator de integração social capaz de diminuir conflitos interculturais e promover o respeito à diversidade e a tolerância entre os povos.

No contexto da dinâmica das línguas nesse início de século, duas realidades têm sido colocadas em cheque: de um lado a necessidade de integração com o mundo exterior que impulsiona os indivíduos a congregar, a confraternizar com o outro, com o diferente e, por outro, a premência de resguardar a identidade, os valores e a cultural local. Na confluência dessas realidades, as políticas linguísticas contemporâneas estão permeadas de contradições e refletem as tentativas de conciliar os interesses locais das comunidades e as demandas globais do mercado linguístico (CALVET, 2002).

Dentre as transformações sociais que envolvem a relação estabelecida entre os indivíduos e as línguas nos dias atuais, Beacco ; Byran (2003) elencam:

a) A formação que se dá ao longo da vida, incluindo aprendi- 
zagem de novas línguas que estão relacionadas tanto às modificações do mercado de trabalho quanto ao crescimento da expectativa de vida;

b) O crescimento da circulação de capital, de bens, de serviços, de pessoas e de ideias, portanto, de línguas, no âmbito da constituição de um espaço midiático internacional e de uma economia global única;

c) A atenção crescente dos direitos das minorias culturais e linguísticas;

d) $\mathrm{O}$ crescimento da demanda social em línguas, valorizadas como componentes do capital profissional ou de qualidade de vida;

e) A difusão internacional de uma língua franca, contrabalanceada pela valorização local de línguas identitárias ou de identificação (línguas comunitárias, regionais, línguas outras, além das línguas estrangeiras mais difundidas) seguindo o princípio da distinção.

Para Beacco (2004), este conjunto de transformações deixa entrever prospectivas contraditórias (homogeneização, diversificação, aniquilamento) nas quais as políticas linguísticas educativas precisam definir seu papel.

Especialmente quando se trata da escolha entre línguas estrangeiras ou segundas línguas, é natural que a opção seja por aquela que representa nível hierárquico superior, o que explica que falantes de línguas supercentrais como o português, o francês e o espanhol optem, em sua maioria pela aprendizagem do inglês. Essa tendência tem provocado desequilíbrios e situações conflituosas entre povos e línguas de regiões vizinhas e regionais. A título de exemplos destacamos a tendência dos poloneses a estudarem inglês e não mais o alemão; dos suíços buscarem cada vez mais o inglês e não uma das línguas regionais oficiais regionais do país. Esse verticalismo exacerbado, segundo Hamel (2010) pode comprometer o desenvolvimento do plurilinguismo e trazer repercussões para a política linguística mundial.

A seguir apontamos algumas políticas que repercutem as contradições vivenciadas pelo confronto entre o global e o local: 


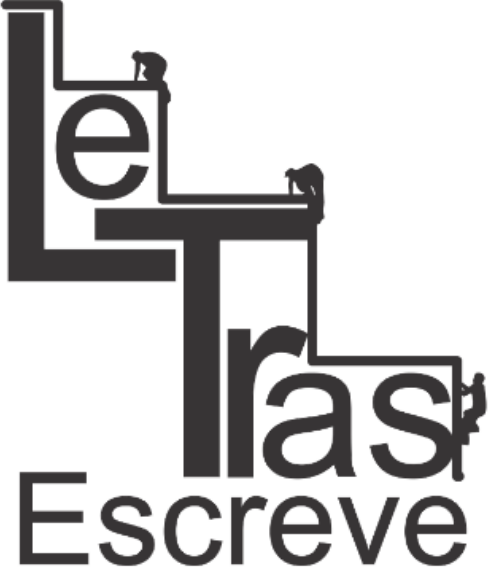

(ISSN 2238-8060)
Comunidade Europeia - Uma tendência mundial está retratada na fórmula encontrada pela União Europeia para o ensino de línguas: sendo o inglês a língua estrangeira obrigatória na maioria dos países membros, a escolha de uma segunda língua estrangeira também «obrigatória» deve ser necessariamente por uma língua regional e não outra língua internacional. Essa estratégia favorece as línguas regionais e pode enfraquecer as línguas oficiais do bloco.

$\checkmark$ MERCOSUL - A tentativa de expandir o uso do português e do espanhol na região culminou no lançamento de políticas linguísticas educativas que tornaram obrigatória a oferta, seja do português em países do bloco, seja do espanhol no Brasil. Em contrapartida, outras línguas regionais e/ ou estrangeiras veem seu espaço retrair-se frente às políticas de expansão das línguas majoritárias.

$\checkmark$ Estados Unidos - Contraditoriamente, a expansão do inglês e seu uso massivo no campo das ciências e da tecnologia tem provocado o crescimento do monolinguismo anglo-saxão, em especial entre os pesquisadores (HAMEL, 2010).

$\checkmark$ Brasil - A busca da conciliação resultou no conflito das políticas oficiais e as de fato. Se a LDB - permite a diversidade e possibilita a escolha da Língua Estrangeira (LE) de acordo com a preferência da comunidade escolar a Lei 11.161/2005 determina a oferta obrigatória da língua espanhola; Mais recentemente a $\mathrm{MP}^{4}$ 746/2016, torna $\mathrm{o}$ inglês a única língua estrangeira obrigatória na educação brasileira. Um retrocesso para a política de plurilinguismo no Brasil.

Especialmente no Brasil, a situação da política linguística bra-

\footnotetext{
${ }^{4} \mathrm{O}$ governo brasileiro reedita uma política do governo militar (ACORDO M EC- USAID)
} 
sileira para o ensino de línguas revela a essência de sua contradição na fronteira franco-brasileira, região onde a política linguística nacional se confronta com a política implementada no estado do Amapá ao longo dos últimos 20 anos e a ecologia linguística da região fronteiriça. As demandas locais pelo ensino da língua francesa conflitam com a política linguística nacional e até global, face à obrigatoriedade de oferta do espanhol, à posição hegemônica do inglês e aos mecanismos do Estado brasileiro para fazer valer sua política de ensino de línguas em toda a extensão do território brasileiro (DAY, 2016).

\section{Considerações finais}

Ao longo deste artigo, procuramos pontuar em linhas gerais os principais eixos de debate no campo das políticas linguísticas educativas na atualidade. Destacamos tanto as discussões epistemológicas que se concentram no escopo da política linguística em si mesmo, quanto às discussões relativas às abordagens consideradas mais ou menos adequadas para as línguas na sociedade.

Nossa reflexão intenta demonstrar que quanto mais se integram as economias nacionais, tanto mais se aprofundam as relações entre os povos. Nesse contexto algumas línguas assumem papéis protagonistas e consolidam suas presenças no mundo globalizado. Todavia, a proximidade real ou virtual, assegurada pela quebra de barreiras de locomoção e de comunicação não diluem as semelhanças e as diferenças construídas ou diluídas ao longo da história das civilizações, das comunidades linguísticas.

De igual maneira, quanto maior a integração, tanto maiores são as influências de uma língua sobre a outra, de uma cultura sobre a outra, descortinando também valores, comportamentos, práticas, preconceitos, etc. assim, cabe reconhecer que as políticas linguísticas educativas da contemporaneidade espelham esses conflitos, tanto aquelas que tratam particularmente das línguas maternas como é o caso das línguas que têm ganhado espaço como co-oficiais 


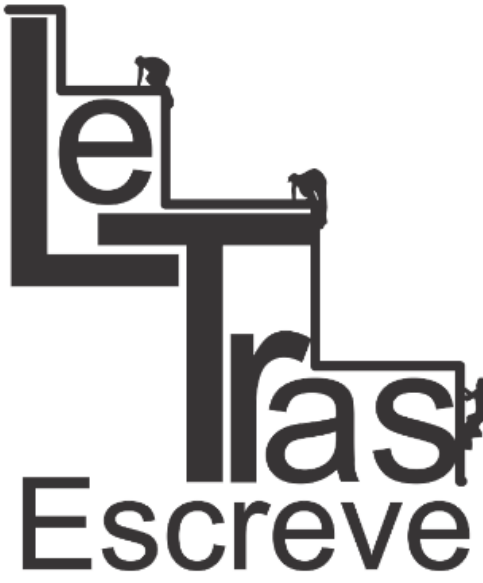

(ISSN 2238-8060)

no Brasil, quanto àquelas que ocupam a função de língua adicional ou estrangeira.

Buscamos demonstrar nessa reflexão que nesse início de século, os projetos educativos locais ou nacionais estão, a cada dia, mais atrelados aos contextos supranacionais dominantes, e estes, por sua vez, vinculados a programas políticos e econômicos que têm na comunicação o elemento central. Na contramão desse processo, muitos estados, empresas e mesmo famílias têm buscado uma orientação alternativa, que paralelamente ao fluxo do mercado global reforcem suas identidades regionais e suas características culturais através do fortalecimento de seus laços linguísticos.

As políticas linguísticas de ensino de línguas tencionadas no momento atual apontam por um lado para o fortalecimento da hegemonia do inglês como língua global (hipercentral) e por outro para o enfraquecimento das demais línguas nacionais (supercentrais) comprometendo, em certa medida a manutenção e a proteção da pluralidade linguística mundial. Cada vez mais, as línguas minoritárias locais e/ou regionais perdem espaço frente ao aparato tecnológico que está a serviço, principalmente, da língua inglesa. Esse ciclo contínuo influencia decisivamente a relação dos indivíduos com suas línguas podendo alterar definitivamente a ecologia linguística de uma região.

Por fim, cabe dizer que toda política linguística se apoia em princípios e objetivos, declarados ou não, conscientes ou não, que vão muito além daqueles puramente linguísticos. Frequentemente elas estão apoiadas em projetos políticos, sociais e econômicos alinhados a um determinado grupo de interesses. Na lógica do mundo contemporâneo, a política do "tudo em inglês", que promove a existência de uma língua de comunicação universal, convém ao raciocínio econômico da atualidade. Ainda assim, na contramão deste pensamento atuam as políticas regionais e locais que tentam estabelecer um regime linguístico diferencial que atue em favor das particularidades e das simetrias ecolinguísticas, tanto no uso quanto no ensino de línguas. 


\section{Referências}

BRASIL. Medida provisória n.ำ746, de 22 de setembro de 2016. Diário Oficial [da] República Federativa do Brasil, Poder Executivo, Brasília, DF, 23 set. 2016. Edição extra 184.

BRASIL. Decreto-lei no 9.394, de 20 de dezembro de 1996. Estabelece as diretrizes e bases da educação nacional. Diário Oficial [da] República Federativa do Brasil, Brasília, DF, 20 de dezembro de 1996.

BEACCO, Jean-Claude. L'Europe des langues aujourd'hui: de technique en politique. Synergies Italie : revue de didactologie des langues-cultures, Turin, $\mathrm{n}^{\circ}$ 1, p. 42-50, 2004. Disponível em < http://gerflint.fr/synergies-italie>. Acesso em : 23 de maio de 2007.

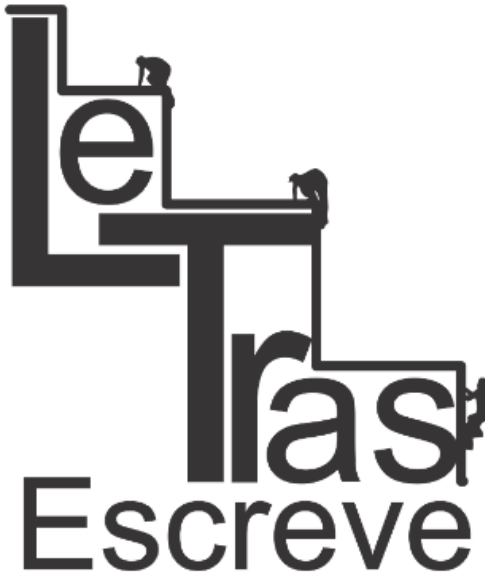

(ISSN 2238-8060)

BEACCO J.-C., BYRAM, M., Guide pour l'élaboration des politiques linguistiques éducatives en Europe, COE, 2003.

BOHN, Hilário. Os aspectos 'políticos' de uma política de ensino de línguas e literaturas estrangeiras. Linguagem \& Ensino, v. 3, n. 1, p. 117-138. Pelotas: Educat, 2000.

CALVET Louis-Jean. Les politiques linguistiques. Paris: PUF, 1996.

CALVET, L.-J. Sociolinguística: uma introdução crítica. trad. Marcos Marcionilo. São Paulo: Parábola Editorial, 2002.

DAY, Kelly. Políticas Linguísticas Educativas em Conflito no Amapá: Impactos e contradiçoes da LDB 9394/96 e da Lei 11.161/2005. 2016, 198f. Tese de doutorado - Universidade Federal Fluminense. Rio de Janeiro, 2016.

HAMEL, R. E. L'aménagement linguistique et la globalisation des langues du monde. Télescope, vol. 16, $n^{\circ} 3$, p. 1-21, 2010.

HAUGEN, E. Planning for a standard language in Norway. Anthropological Linguistics, v. 1, n. 3, pp. 8-21, 1959.

HAUGEN, E. The Ecology of language. Standford, Standford University press, 1972.

PACHECO, José A.; PEREIRA, Nancy. Globalização e identidade no 


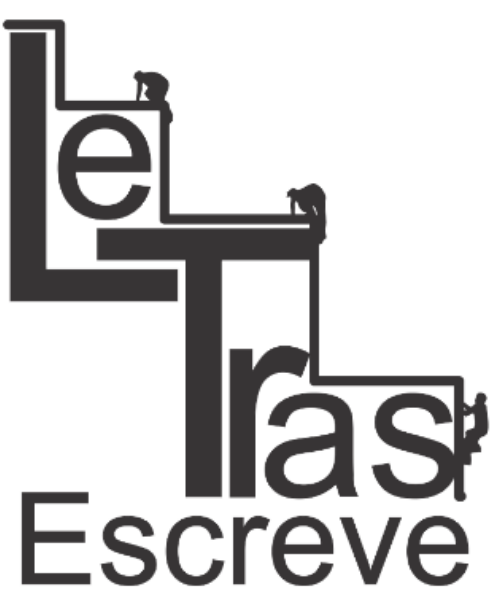

(ISSN 2238-8060)

contexto da escola e do currículo. Cadernos de pesquisa, vol.37, no.131, p. 371 -378, São Paulo May/Aug. 2007. Disponível em: <http://www.scielo.br/pdf/cp/v37n131/a0837131.pdf>. Acesso em 27 de novembro de 2013.

RAJAGOPALAN, K. A geopolítica da língua inglesa e seus reflexos no Brasil: por uma política prudente e propositiva. In: LACOSTE, Y (Org.). A geopolítica do inglês. São Paulo: Parábola Editorial, 2005. p. 135-159.

SAVEDRA, M.M; LAGARES, X. Política e planificação linguística: Conceitos, terminologias e intervenções no Brasil. Revista Gragoatá, Niterói: EdUFF, № 32, p. 11-27, 2012.

SCHIFFMAN, H. F. Linguistic culture and Language Policy. London: Routledge, 1996.

SHOHAMY, E. Language policy: hidden agendas and new approaches. London: Routledge, 2006.

SILVA, Elias Ribeiro da. A pesquisa em política linguística: histórico, desenvolvimento e pressupostos epistemológicos. Trab. linguist. apl. [online]. 2013, vol.52, n.2, pp.289-320. ISSN 2175-764X. Acesso em 22 de novemvro de 2015.

SPOLKY, B. Language Policy. Cambridge: Cambridge University Press, 2004.

Recebido em: 30 de novembro de 2016

Aprovado em: 23 de janeiro de 2017 